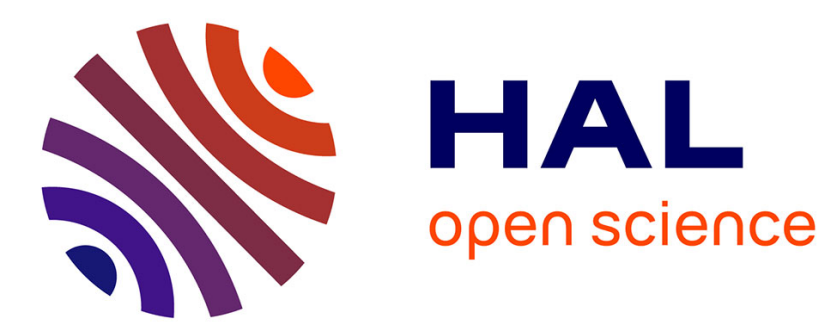

\title{
La parenté en l'an mil
}

Martin Aurell

\section{- To cite this version:}

Martin Aurell. La parenté en l'an mil. Cahiers de Civilisation Médiévale, 2000, XLIII (170), pp.125142. 10.3406/ccmed.2000.2775 . halshs-00598810

\section{HAL Id: halshs-00598810 https://shs.hal.science/halshs-00598810}

Submitted on 17 Jun 2016

HAL is a multi-disciplinary open access archive for the deposit and dissemination of scientific research documents, whether they are published or not. The documents may come from teaching and research institutions in France or abroad, or from public or private research centers.
L'archive ouverte pluridisciplinaire HAL, est destinée au dépôt et à la diffusion de documents scientifiques de niveau recherche, publiés ou non, émanant des établissements d'enseignement et de recherche français ou étrangers, des laboratoires publics ou privés. 


\section{La parenté en l'an mil}

Martin Aurell

\section{Citer ce document / Cite this document :}

Aurell Martin. La parenté en l'an mil. In: Cahiers de civilisation médiévale, 43e année (n¹70), Avril-juin 2000. Regards croisés sur l'An Mil. pp. 125-142;

doi : 10.3406/ccmed.2000.2775

http://www.persee.fr/doc/ccmed_0007-9731_2000_num_43_170_2775

Document généré le 01/06/2016 


\title{
Résumé
}

L'étude de la parenté de l'an mil a été considérablement renouvelée par les travaux récents. Le cousinage de l'époque carolingienne, à faible profondeur généalogique, présente une conscience et une mémoire matrilinéaires ; il pousse ses membres à l'itinérance et privilégie les stratégies matrimoniales isogamiques et endogamiques. Par contraste, le lignage, issu d'une radicale mutation sociale, se caractérise par son agnatisme, un nouvel accent mis sur la filiation patrilinéaire. II sédentarise et individualise des lignées familiales autour du château, devenu leur point d'ancrage. II encourage l'hypergamie et l'avunculat. Enfin, cette évolution s'accompagne de l'action menée par le clergé pour christianiser le mariage : indissolubilité et unicité mettent en cause les stratégies matrimoniales et patrimoniales de l'aristocratie.

\begin{abstract}
Our knowledge of kinship around 1000 has been deeply renewed by recent studies. The Sippe of the Carolingian period, which genealogical deepness is feeble, presents a matrilineal awareness and memory. It fosters nomadism and isogamic and endogamic matrimonial strategies. Nonetheless, the lineage, born in a radical social mutation, is defined by agnatism, a new stress on patrilineal filiation. It becomes sedentary and individualises the familial dynasties in the castle, in which they take root. It encourages hypergamy and avunculat. This evolution is related with the action of the clerks in order to do the marriage more Christian. Indissolubility and unity attack the patrimonial and matrimonial strategies of aristocracy.
\end{abstract}




\title{
La parenté en l'an mil
}

\begin{abstract}
RÉSUMÉ
L'étude de la parenté de l'an mil a été considérablement renouveléc par les travaux récents. Le cousinage de lépoque carolingienne, à faible profondeur généalogique. présente une conscience ct une mémoire matrilinéaires: il pousse ses membres à l'itinćrance et privilégic les stratégies matrimoniales isogamiques et endogamiques. Par contraste, le lignage, issu d'une radicale mutation sociale, se caractérise par son agnatisme, un nouvel accent mis sur la filiation patrilinéaire. Il sédentarise et individualise des lignées familiales autour du château, devenu leur point d'ancrage. Il encourage l'hypergamie et l'avunculat. Enfin, cette évolution s'accompagne de l'action menée par le clergé pour christianiser le mariage : indissolubilité et unicité mettent en cause les stratégies matrimoniales et patrimoniales de l'aristocratic.
\end{abstract}

\section{ABSTRACT}

Our knowledge of kinship around 1000 has been deeply renewed by recent studies. The Sippe of the Carolingian period, which genealogical decpness is feeble, presents a matrilineal awareness and memory. It fosters nomadism and isogamic and endogamic matrimonial strategies. Nonetheless, the lineage, born in a radical social mutation, is defined by agnatism, a new stress on patrilineal filiation. It becomes sedentary and individualises the familial dynasties in the castle, in which they take root. It encourages hypergamy and avunculat. This evolution is related with the action of the clerks in order to do the marriage more Christian. Indissolubility and unity attack the patrimonial and matrimonial strategies of aristocracy.

$\mathrm{Au}$ cours des trois dernières décennies, la connaissance de la famille des $\mathrm{x}^{\mathfrak{c}}$ et $\mathrm{xI}^{\mathrm{e}} \mathrm{s}$. s'est considérablement enrichie. À l'occasion du deuxième millénaire, le comité de rédaction de notre revue a considéré que le temps était venu de faire le point sur ce renouvellement historiographique. Les pages qui suivent essaient, tant bien que mal, de répondre à cette demande. Elles prétendent à la synthèse, et par voie de conséquence elles ne peuvent paraître que schématiques. Elles tentent, en effet, de dégager un modèle de portée générale qui risque, par la force des choses. d'être opposé aux contre-exemples de telle ou telle monographie. Qu'on nous permette cependant de contourner d'emblée cet écueil épistémologique en avançant que, à la mode de l'anthropologie de la parenté, c'est en termes de tendances qu'il faut raisonner afin de présenter ces constructions sociales et culturelles que sont la filiation (transmission des biens immatériels et matériels entre consanguins) et l'alliance (échange de femmes entre deux groupes de parenté).

Ces prémisses de méthode étant posées, force est de constater combien les spécialistes de la famille médiévale fondent aujourd hui leurs travaux sur des problématiques rajeunies. Aucun d’entre eux n'oserait plus adopter le discours flagorneur des généalogistes de l'Ancien Régime à l'égard de la maison commanditaire de leur étude, si tant est que ces mécènes existent encore. Il ne serait pas. non plus, de mise de rédiger une monographie familiale se limitant à reconstituer 
un tableau de filiation ou schéma d'apparentement ', sans entreprendre aucune réflexion large et comparatiste. Nul arbre généalogique ne cache désormais l'immense forêt, fertile en découvertes, de l'histoire de la famille replacée dans un contexte global. Peut-être faut-il, en France, trouver une fois de plus le début de ce renouveau dans l'œuvre de Marc Bloch. Les pages qu'il rédige sur les «liens du sang» ou sur la «solidarité du lignage» dans La société féodale (1939) n'ont guère perdu de leur fraîcheur. Elles insistent sur la "vigueur extrême " des relations qui unissent, au moyen âge, les membres d'un groupe de parents, "comme si, en vérité, il n'y avait d'amitié véritable qu'entre personnes unies par le sang " 2 .

À la veille de la Seconde Guerre mondiale, ce chapitre fondateur doit beaucoup à une double interdisciplinarité, qui adapte la démarche des historiens du droit et des ethnologues à l'investigation du médiéviste. D'une part, l'attrait intellectuel des juristes pour la famille est toujours inhérent à leur pratique du droit. Les civilistes traquent ainsi, de longue date, dans la coutume et dans la doctrine médiévale les origines du régime patrimonial qui régit les relations économiques entre époux, entre parents et enfants ou entre cousins ${ }^{3}$. L'intérêt des canonistes est tout autre : il se porte sur le droit ecclésiastique du mariage et sur son application ${ }^{4}$. D'autre part, depuis ses origines, l'anthropologie culturelle a considéré la parenté comme l'un de ses thèmes primordiaux, si ce n'est comme le principal. Elle a ćlaboré des modèles et typologies, et elle s'est dotée d'outils conceptuels et d'un vocabulaire, auxquels peuvent facilement avoir recours les autres sciences humaines ${ }^{5}$. Dans lcurs travaux, quelques médiévistes se sont, par exemple, largement inspirés de la théorie générale de Claude Lévi-Strauss sur l'échange de femmes dans les sociétés archaïques pour décrire les stratégies matrimoniales de l'aristocratie ${ }^{6}$. Point d'orgue de cette collaboration. l'ethnologue anglais Jack Goody, spécialiste des sociétés africaines, publie en 1983 un ouvrage sur l'influence des normes de l'Église médiévale sur la parenté 7 . Même s'il surprend par ses positions matérialistes, cet ouvrage mérite d'être relevé, car il a grandement contribué au dialogue entre historiens et anthropologues. Cette collaboration n'est pas toujours facile ${ }^{8}$ : les uns fondent, en effet, lcur méthode sur la diachronie et les autres sur la synchronie; les uns privilégient l'érudition et le commentaire des documents et les autres construisent leurs modèles sans les fonder toujours sur les enquêtes de terrain. Cette association de disciplines apporte, néanmoins, aux spécialistes de l'Occident médiéval un ensemble de questions passionnantes qu'ils n’auraient jamais osé poser à leurs sources.

1. Ces deux expressions somt préférables aux désuets "arbres généalogiques». car elles mettent l'accent sur l'élaboration a posteriori de la filiation et laalliance sous forme de tableau par l'historien actuel. Le mot "généalogie " est réservé ici aux seuls écrits médiévaux sur les familles et au fonctionnement de la mémoire qu ils laissent transparaitre.

2. M. Bı.och, La société féodale. 6c éd.. Paris, 1978, p. 183-208, et p. 184 pour la citation.

3. R. Ginestat., Le parage normand, Caen. 1911: - L. Falıtesı, Le retrait lignager en droit coutumier français, Paris. 1923: - J. YuE. Égalité entre héritiers et exclusion des enfants dotés. Esscii de géographie coutumière, Paris. 1966: -

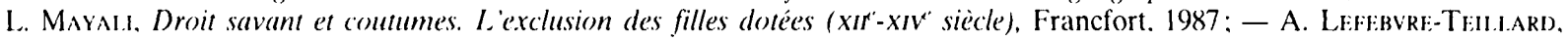
Introduction historique au droit des personnes et de la famille, Paris, 1996: - M. A. Bermfso Castrilio. Parentesco, matrimonio, propiedad y herencia en la Castilla altomedieval, Madrid. 1997.

4. A. Esma:n, Le mariage en droit canonique, Paris. 1891; - P. Daudet, L'établissement de la compétence de l'Église en matière de divorce et de consanguinité. Paris. 1941: - J. Gaudemrt. Sociétés et mariage, Strasbourg. 1980). el Le mariage en Occident. Paris. 1987.

5. A. Gutrkenu-Jalabert, "Sur les structures de parenté dans l'Europe médiévale ". Annales ESC, 36.1981. p. 1028-1049. On trouve une initiation facile aux méthodes et au vocabulaire de l'ethnologic dans R. Fox. Anthropologie de la parenté. Une analyse de la consanguinité et de l'alliance, Paris, 1972.

6. Les structures élémentaires de la parenté. Paris. 1949. et son utilisation par J. F. Rur-Domf́Nec. "Système de parenté et théorie de l'alliance dans la société catalane (env. 1000-env. 1240) ». Revue historique. 532. 1979. p. 305-326.

7. L'évolution de la famille é du mariage en Europe, Paris, 1985, où il est avancé que, en formulant des règles contre ke mariage consanguin et en faveur du célibat des prêtres ou en décourageant l'adoption. l'Église cherche à capter la plupart des héritages. dispersés par l'exogamie ou par l'absence d'héritiers directs. Tout en reconnaissant le rôle que cette institution joue, par lassistance et la charité. dans la redistribution des richesses au moyen âge. force est de constater qu une explication exclusivement centrée sur des considérations matériclles rend difficilement compte d'un phénomène complexe largement conditionné par une doctrine biblique et par une réflexion théologique qui suit sa propre logique

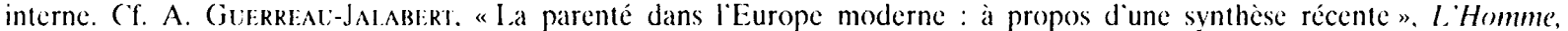
29. 1989. p. 69-93.

8. (f. quelques-unes des discussions entre médiévistes et anthropologues transcrites dans les Actes du colloque de Paris de 1974. Famille et parenté dans l'Occident médiéval, éd. (j. DuBY et J. I.F Gofr. Rome, 1977, p. 35-40. 
Pour les $x^{\mathfrak{e}}$ et $\mathrm{XI}^{\mathrm{e}}$ s., cette documentation les déçoit souvent. Elle ne les éclaire guère que sur la noblesse. Elle ne comprend, d'ailleurs, que très peu de généalogies au sens strict, élaborées à la gloire des nobles par leurs contemporains : précieuses, ces listes de descendants d'un ancêtre commun sont amplifiées parfois de détails sur la biographie de ces personnages: elles nous renscignent davantage sur le fonctionnement de la mémoire de la famille que sur son organisation réelle". Elles se rapprochent souvent de l'historiographie au sens strict, alors que la plupart des chroniques se limitent encore à exalter les hauts faits d'une lignée princière. Pour connaître les pratiques vécues de la parenté, force est donc d'avoir recours aux actes de la pratique, qui mentionnent parfois les liens de filiation et d'alliance qu'unissent entre eux les individus des couches aristocratiques de la société. En l'absence presque totale d’archives familiales privées, ces documents doivent être puisés dans les chartriers et cartulaires ecclésiastiques. Ils ne sont pas exempts de manipulations et interpolations ${ }^{10}$. Certains d'entre cux, rédigés au passé sous forme de notice. rappellent même les généalogies : le cartulaire de l'abbaye provençale de Lérins recèle. par exemple. le récit des donations grâce auxquelles ce monastère récupère, vers 1125 , le village de Vallauris; chemin faisant, son scribe retrouve quatre générations de la maison des vicomtes de Grasse dont il a reçu peut-être la charge de préserver à jamais la mémoire "1. Mais la plupart de ces chartes semblent dressées au moment même où se crée l'acte juridique qu'elles sont censées entériner. En particulier, les constitutions de douaire ou les testaments, certes pas toujours nombreux. contiennent des données immédiatement utilisables par l'historien de la parenté. Les chartes foisonnent, en somme, de renseignements sur la famille 12.

C'est à partir d'elles qu'on élabore habituellement les schémas d'apparentement, préalable obligé à toute recherche. Ce travail n'est pas toujours aisé pour des époques où le système onomastique, loin d'être explicite ou figé, empêche d'appréhender avec certitude les relations de paternité, fraternité ou cousinage. Les médiévistes n'en considèrent pas moins que trois indices - aussi ténus soient-ils - déterminent la parenté d'individus cités par les chartes : adoption des mêmes noms, occupation des mêmes terres et accaparement des mêmes charges politiques. Si, par ce biais, ils parviennent d'abord à restituer la filiation, il leur faut ensuite découvrir l'alliance, tâche encore plus ardue. En effet, la plupart du temps, les mentions documentaires des femmes n’interviennent qu'après leur mariage, virilocal à quelques exceptions près, qui les contraint à quitter leur famille d'origine pour celle de leur époux et donc à s'éloigner; rares sont ainsi les sources qui permettent de retrouver leur géniteur ${ }^{13}$. La femme, sous-représentée dans les sources ${ }^{14}$, est la moins connue des acteurs sociaux de la parenté de l’an mil.

9. L. (Brivior. Les généalogies, Turnhout. 1975 (Typologie des sources du Moyen Áge occidental. 15). avec 14 pages de mise à jour en 1985. Pour les $x^{\circ}$ et $x^{\circ}$ s.. il ne subsiste à peine de ces textes que ceux qui ont été élaborés dans les abbayes flamandes de Saint-Bertin et de Saint-Pierre de Gand.

i0. D. Barthélemy insiste ainsi sur la forte influence de la mentalité monastique et sur ses mutations dans la rédaction de ces actes de la pratique. en apparence si objectifs. La société dams le comté de Vendôme de lan mil au sn' siècle. Paris. 1993. p. 19-127. Sur le poids des différentes autorités dans la production documentaire. cf. O. (ityotJisivis. "Penuria scriptorum. Le mythe de l'anarchie documentaire dans la France du Nord ( $x^{\circ}$-premiere moitié du $x^{\circ}$ s.)". Bibliotheque de l'École des Chartes, 155. 1997. p. 11-44.

11. P. J. Giakr. La mémoire et l'oubli à la fin du premier millénaire. Paris. 1996. p. 124-127.

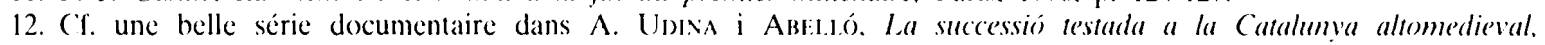
Barcelone. 1984.

13. Sur la méthode de reconstitution des schémas dapparentement. ef. S. de VAlAY. "Comtesses dorigine occitane dans la marche d'Espagne aux $x^{\prime}$ et $x^{\prime \prime}$ s." Hidalguia, 162-163. 1980). p. 585-616. 755-788: - (h. Slitipani. Nos ancêtres de lAntiquité. finudes des possibilités des liens généalogiques entre les familles de lantiquité et celles du haut Moven Âge éuropéen, Paris. 1991. et La préhistoire des Capétiens, Villeneuve d'Ascq. 1999. ainsi que de nombreux articles que la revue Medieval Prosopography, publiée à l'Université de Michigan depuis 1980. consacre à la reconstitution des familles. Nous nous permettons, de même, de renvoyer à M. Atrkf1.1. "Jalons pour une enquéte sur les stratégies matrimoniales des comtes catalans ( $\mathrm{XX}^{\circ}-\mathrm{XI}^{\circ}$ s.)". dans Symposium internacional sobre els origens de (atalunya (segles Vill-XI), Barcelone. 1991. T. I. p. 281-364. et "Du nouveau sur les comtesses catalanes (IX"-XII" s.)". Annales du Midi. 109. 1997. p. 357-380).

14. A titre dexemple pour le $x^{\mathrm{c}}$ s.. sur les 2.607 noms du cartulaire galicien du monastere de (elanova, seuls 323. soit $12 \%$. correspondent à des femmes. M. del (. PAl.AkEs. Ilduara, una aristócrata del siglo X. I a Corogne. 1998. p. 53. Ce monastere est certes d hommes mais. méme dans les rares cartulaires de communautés féminines. les noms de femmes restent minoritaires. D. BAkmf́llmy, "F́léments danthroponymie féminine daprès le cartulaire du Ronceray d'Angers (1028-1124 environ)". dans (ienèse médiésale de lanthroponymie moderne, éd. M. Bot kIx. 1. II-2. Tours. 1992. p. 68. 
En définitive, ces difficultés d'ordre documentaire exigent une analyse serrée des textes. Mais, en dépit d'une telle rigucur, la part de l'hypothèse et de l'interprétation restera toujours grande dans les monographies des familles de l'an mil. Parues récemment, quelques publications montrent toutefois que ces obstacles ne sont pas insurmontables. Elles dégagent un certain nombre de conclusions sur le cousinage, système de parenté de la période carolingienne, sur son remplacement par le lignage, concomitant à l'effondrement du pouvoir royal et princier, et sur les transformations que la christianisation de la société apporte aux pratiques matrimoniales.

\section{Cousinage : cognatisme, itinérance et indivision}

L'étude de la parenté du haut moyen âge doit beaucoup à l'historiographic allemande. À partir des années cinquante, aux universités de Fribourg-en-Brisgau et de Münster, Gerd Tellenbach et ses élèves élaborent un programme de recherche en prosopographie, dont le but est de reconstituer les carrières militaires, administratives et ecclésiastiques de la noblesse carolingienne (Reicharistokratie) 1.5. Leur investigation sur les mécanismes de pouvoir du groupe aristocratique débouche nécessairement sur la parenté : elle met ainsi l'accent sur la continuité des familles de la noblesse impériale depuis des temps immémoriaux (Uradel), sur leurs liens de consanguinité el d'affinité avec les Carolingiens ou sur l'absence d'une organisation linéaire et agnatique (priorité accordée à l'ascendance et descendance par le père) de la parenté aristocratique avant l'an mil. Ces thèses ont été reprises ou discutées dans l'ouvrage, facile d'accès. que Régine Le Jan a consacré, en 1995, aux structures familiales dans le monde franc des $\mathrm{VII}^{\mathrm{C}}-\mathrm{X}^{\mathrm{C}} \mathrm{s} .1 \mathrm{k}$.

De telles idées rendent désuète la dialectique entre la "famille nucléaire » et la "famille élargie", qui a longtemps prévalu dans les études sur la parenté. L'individu apparait désormais inséré dans plusicurs groupements de parents à dimension variable, qui s'emboîtent les uns les autres. Au niveau inférieur, les chercheurs décrivent la familia ou groupe domestique, la plus élémentaire des unités sociales, qui ne se limite pas au couple et à ses enfants, mais qui comprend le chef de famille, son épouse légitime et ses concubines (Friedelfraten), des enfants nés de ces unions, des parents de la génération précédente, des jeunes et nourris, des domestiques et esclaves... ${ }^{17}$. Dans un espace régional déterminé, plusieurs de ces familles, apparentées et voisines, étroitement solidaires, constituent une stirps, terme qu'on serait tenté de traduire par "clan " ${ }^{18}$. Enfin, chaque groupement local de familles a conscience d'appartenir à une parentèle, encore plus vaste et large que la stirps, couvrant l'ensemble de l'Empire. Ce groupe supérieur de la hićrarchic familiale apparaît dans les sources sous les noms de gens, genus, progenies ou prosapia. On le retrouve, par exemple, chez les Agilolfides (gens nobilis Ayglofinga), qui se veulent tous descendants du roi franc Agiulf $(\div 457)$ : les membres de cette parentèle sont présents en Ncustric où ils se perpétuent dans la famille des comtes de Meaux, en Austrasie où ils figurent parmi les ennemis déclarés des Pippinides, en Italie où ils deviennent rois de Lombardie, ainsi qu'en Alémanie et

15. G. Tem.t.ivbach. Kinigtum und Stämme in der Werdezeit des deutschen Reiches, Weimar. 1939: "From the Carolingian Imperial Nobility to the German Estate of Imperial Princes ». dans The Medieval Nobility. Studies on the Ruling Classes of France and Germany from the Sixth to the Twelfth Century, éd. Th. REctTer. Amsterdam. 1979, p. 203-242: et Ausgewählte Abhandlungen und Alifsaitze. Stuttgart. 1988-1989: - K. Scryid, "The Structure of the Nobility in the Earlier Middle Ages". dans The Medieval Nobility..., p. 37-59: - J. Wol.LAsch. "Les obituaires. témoins de la vie clunisienne". Cahiers de civilisation médiévale, 22. 1979. p. 139-171. et "Parenté noble et monachisme réformateur. Observations sur les conversions à la vie monastique aux $\mathrm{XI}^{\circ}$ et $\mathrm{xII}^{\circ}$ siècles ". Revue historique. 535, 1980), p. 3-24: -

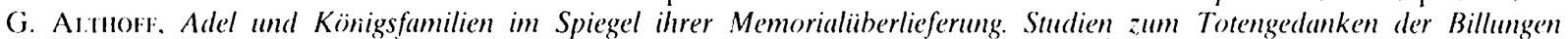
und Ottonen. Munich. 1984: - O. G. Orxi.f. "Les groupes sociaux du Moyen Âge el les débuts de la sociologie contemporaine". Annales ESC, 47, 1992. p. 751-765; - K. F. WfikNek. Naissance de la noblesse. Paris. 1998.

16. Famille et pouvoir dans le monde franc (vir'- $x^{\prime \prime}$ s.). Essai d'anthropologie sociale. Paris. 1995.

17. Ihid.. p. 341 .

18. M. Heimzirmanv. "La noblesse du Haut Moyen Âge ( $\mathrm{vII}^{\circ}-\mathrm{xl}^{\circ}$ s.). Quelques problèmes à propos d'ouvrages récents". Moyen Âgé, 83. 1977. p. 139. Pour la plupart des ethnologues, cependant. le «clan". division de la tribu. renvoie à un groupe de parenté qui se dit descendre d'un ancêtre commun. sans quil sache remonter à lui en désignant tous les maillons qui l'en séparent : cette définition correspond plutôt au " cousinage". 
en Bavière où ils accaparent les charges ducales ${ }^{19}$. Or, ce groupe tentaculaire de parents et alliés traduit la plus caractéristique des structures de parenté de la noblesse occidentale du haut moyen âge. Le terme par lequel l'historiographie allemande le désigne est Sippe, qu'on traduit habituellement par «cousinage".

La Sippe présente un trait spécifique qui la différencie de la gens romaine, fortement patriarcale. Par contraste. elle est cognatique ou bilatérale : les ascendants masculins y comptent autant que les féminins. Prenons le cas des Libri memoriales de Fulda et de Reichenau. dont l'édition et l'analyse devinrent le point de départ de l'École de Fribourg. Il s'agit là d'un catalogue de noms à usage liturgique, inclus dans la prière commémorative des défunts; on y retrouve plusieurs milliers d'ecclésiastiques et de princes, mais aussi des donateurs ou visiteurs du monastère, mis en relation avec leurs ancêtres et parents ${ }^{20}$. L'intérêt de l'agencement de ces listes onomastiques est qu'elles mettent sur un pied d'égalité tous les consanguins, que ce soit par ligne paternelle ou maternelle. $\mathrm{Ce}$ cognatisme transparaît, de même, dans la diplomatique ou l'hagiographic : en 922. une donation de Charles le Simple en faveur de Saint-Maur-des-Fossés rappelle que le comte Begon, l'arrière-grand-père de sa mère (genitricis nostrae proavus), avait jadis restauré ce monastère; vers 1012. Constantin. biographe d'Adalbéron (984-1005), évêque de Metz, rattache le saint à la famille impériale, en raison de sa grand-mère maternelle Hadwige, fille d'Henri I ${ }^{\text {er }}$ (919-936)... ${ }^{21}$. Des flottements sémantiques abondent parfois dans ce sens : en 739, dans son testament, le patrice provençal Abbon n'établit plus la distinction entre patruas (oncle paternel) et avunculus (oncle maternel). termes qu'il utilise de façon égale 22 . Pris parmi tant d'autres, ces exemples montrent la place des ancêtres par les femmes dans la conscience généalogique de l'aristocratie du $\mathrm{x}^{\mathrm{c}} \mathrm{s}$. Dans le cousinage, la mémoire familiale ne privilégie pas particulièrement les aïeux agnatiques. Elle est indifférenciée.

L'onomastique le prouve. Le seul nom donné à l'enfant provient aussi bien de la parenté du père que de la mère. Dès l'Antiquité tardive, cet anthroponyme unique est composé de deux éléments accolés (une racine et une finale), chacun d'entre eux possédant sa signification propre. Souvent, l'une de ces deux composantes renvoie aux cognats : Madelberte, fille de sainte Waldetrude (626-686), abbesse de Mons, porte ainsi la racine du nom de son père (Madelgaire), suivi de celle de sa grand-mère maternelle (Bertille) ${ }^{23}$. À la fin du $\mathrm{IX}^{\mathrm{C}} \mathrm{s}$., ces noms duels se figent cependant, et ils sont désormais transmis sous une forme inchangée 24 . Or, la disparition du principe de variation n'efface pas d'un trait le cognatisme dans la dénomination des personnes, même si cette référence matrilinéaire se manifeste d’une autre façon. Ainsi, Megingaud, comte de Oberrheingau, époux de la soeur de Robert le Fort (†866), appelle l'un de ses fils Robert; les garçons d'Herbert II de Vermandois $(† 943)$ et d'Adèle, fille de Robert I ${ }^{\text {er }}$, portent également les noms robertiens d'Eudes et Hugues ${ }^{25}$. L'importance des femmes dans l'appellation des enfants est donc indéniable. Trop souvent, l'onomastique maternelle renvoie à un ancêtre prestigieux (Spitzenahn) dont le groupe de parents tire son illustration première et peut-être sa force surnaturelle (Hail), même si ce charisme païen est, au $\mathrm{x}^{\mathfrak{C}} \mathrm{s}$., assimilé à la sainteté chrétienne ${ }^{26}$.

Dans un tel contexte la femme devient vecteur de renommée et de noblesse. Lidée qu'on se fait d'elle n'est nullement négative ou de second rang. Elle peut même présenter une dimension militaire. comme dans la mythologie germanique, où les Walkyries renaissent pour conseiller les

19. LE JAN. Famille (voir n. 16). p. 387-395.

20. Scrumin, "The Structure" (voir n. 15). p. 42-45.

21. Recueil des actes de Charles III le Simple, roi de France. 893-923, éd. P. L.alter. Paris. 1940-1949. n" 108: Cossmavis. Vita Adalberonis II, Mettensis episcopi. M.G.H. S.S. IV. p. 664. cités par Li Jas. Famille (voir n. 16). p. 43-44.

22. P. Giany. Aristocracy in Provence : The Rhone Basin at the Dawn of the Carolingian Age, Stuttgart/Philadelphic. 1985: - P. Gitchard). "Fondements romains de la conception de la famille au Haut Moyen Âge". dans Histoire de la famille. éd. ('. Livi-Stratss et (i. Dizi. Paris, 1986. 1. 1. p. 280.

23. I.t: Jas. Famille (voir n. 16). p. 194.

24. Herwzimasx. "la noblesse" (voir n. 18). p. 140.

25. L.: JAs. Fimille (voir n. 16). p. 183 et 217.

26. F. Insigit:k. "On the Aristocratic Character of Early Frankish Society". dans The Medieval Nebility (voir n. 15). p. $113-114$. 
combattants après s'être réunies sur la colline du cousinage (Sippenberg) ${ }^{27}$. Mais les femmes sont surtout les dépositaires de la mémoire familiale. Puisqu'elles transmettent souvent le sang royal et la qualité nobiliaire, elles deviennent, tout logiquement, les gardiennes du souvenir des aïeux, fondateurs du cousinage. Elles hébergent les poètes qui chantent les gestes des anciens et les exploits des rois, comme cette noble frisonne de la Vita Luidgeri d'Altfrid qui prend en charge un barde aveugle. C'est à la demande expresse de l'abbesse Gisèle, sœur de Charlcmagne, que les Annales de Metz, rapportant les débuts de la famille carolingienne, ont été couchées par écrit ${ }^{28}$. Toutes ces traditions se perpétuent au $x^{\mathfrak{e}}$ s. Achevées vers l'an mil, les enluminures du sacramentaire de l'évêque Warmund d'Ivrée mettent en valeur la place des femmes auprès des mourants et dans les cortèges funéraires. Mais ce n'est pas seulement en tant que pleurcuses qu'elles manifestent de façon publique leur affliction ${ }^{29}$. Les hagiographes des reines ottoniennes Mathilde ou Adélaïde en font des veuves pieuses qui remémorent la nécrologie de la famille et qui obtiennent des suffrages des communautés religieuses pour ses défunts ${ }^{30}$. Comme tant de dames de l'aristocratie, elles veillent, de la sorte, à ce que les morts ne tombent pas dans l'oubli des vivants. Elles établissent la jonction entre l'au-delà et l'en deçà.

Ce rôle de la dame dans la construction généalogique répond à des pratiques matrimoniales précises. La haute aristocratie est, en effet, souvent apparentée par les femmes à la famille du roi, proximité royale (Königsnähe) qui assure de remarquables ascensions politiques, tandis qu'émergent les principautés territoriales. Les Udalrichides doivent ainsi leur succès au mariage d'Hildegarde à Charlemagne (768-813), les Welfs à celui de Judith à Louis le Pieux (814-840) et les Bosonides à celui de Richilde à Charles le Chauve (843-877). Ces trois exemples d'hypogamie (mariage d'un homme à une femme de rang inférieur au sien) ne doivent pas nous faire oublier que les mariages des aristocrates aux filles de la famille royale sont aussi fréquents. Le plus célèbre d'entre eux met en scène le rapt, puis les épousailles, de Judith, fille de Charles le Chauve, par Baudouin Bras de Fer $(\$ 878)$, fondateur de la lignée indépendante des comtes de Flandre. Enfin, les mariages isogamiques, entre égaux, semblent se développer au $x^{\mathfrak{c}}$ s., où ils deviennent majoritaires ${ }^{31}$. Au sein des familles princières, ils sont un moyen de souder les cousinages qui, au même niveau de la hiérarchie des pouvoirs, essaient de constituer des principautés territoriales indépendantes. Ils entraînent une endogamie (alliance entre consanguins) particulièrement poussée à l'intérieur des parentèles de la haute aristocratie, qui éloigne du contrôle royal les offices politiques et les terres du fisc ${ }^{32}$.

Chaque Sippe regroupe de nombreux aristocrates, consanguins et alliés. Comme pour les Agilolfides, la dispersion géographique de ce complexe familial peut devenir considérable. Bon nombre d'entre eux sont composés par des nobles originaires d'Austrasie, alliés par mariage aux Pippinides; ils servent par la suite Charlemagne et ses descendants dans l'ensemble de l'Empire, et ils essaiment dans des régions fort éloignées où ils représentent le pouvoir royal. Les Widonides proviennent de Rhénanie, où ils conservent le monastère de Hornbach, mais ils s'installent aussi en Neustrie. sur la marche de Bretagne, ou en Italie, dans le marquisat de Spolète ${ }^{33}$. Leur histoire est similaire à celle des Robertiens, comtes d'Oberrheingau, les ancêtres des Capétiens, implantés dans le pays de la Loire et de la Seine au début du $\mathrm{IX}^{\mathrm{C}} \mathrm{s} .{ }^{34}$. La noblesse impériale est donc en perpétuel nomadisme. Le voyage est inhérent au cousinage, dont les membres se déplacent de part et d'autre de l'Empire, puis du royaume ou de la principauté territoriale, au gré des carrières

27. J.-P. Cuvil.tier, " L'Europe barbare", dans Histoire de la famille (voir n. 22), p. 304.

28. LI: JAN, Famille (voir n. 16), p. 54-56.

29. Giany, la mémoire (voir n. 11), p. 91-98.

30. P. Cokbitr. Les saints ottoniens. Sainteté dynastique, sainteté royale et saintéé féminine autour de l'an mil, Sigmaringen. 1986 (Beihefte der Francia, 15).

31. " $\AA$ partir du milieu du $\mathrm{IX}^{*}$ s.. les turbulences qui agitèrent le milieu aristocratique accrurent les contraintes homogamiques, bloquant ainsi le renouvellement de la noblesse au moment même où le pouvoir royal s`affaiblissait...". L.: JiN. Famille (voir n. 16). p. 327.

32. M. Alris1.. Les noces du come. Mariage et pouvoir en Calalogne. Paris. 1995. p. 44-51.

33. I.: JAN, Famille (voir n. 16). p. 248-249.

34. K. F. Wirner. "I.es premiers Robertiens et les premiers Anjou ( $1 x^{*}$ s.début $x^{c}$ s.) ". dans Pays de looire et Aquitaine de Robert le Font aux premiers Capétiens, éd. R. Favrfal et O. Gtintot, Poiticrs. 1997. p. 9-67. 
déterminées par l'autorité politique ou des domaines fonciers (honores) qu'elle leur cède. Sous les derniers Carolingiens, cette mobilité est essentielle dans la définition de la parenté aristocratique. Même au niveau le plus inférieur, celui de la familia, l'itinérance est de mise, tandis que le chef. ses femmes, ses enfants et ses domestiques visitent leurs différents domaines au fil des saisons, se rendent chez leurs autres parents ou séjournent périodiquement à la cour princière.

Cette mobilité est accrue par la circulation, très fluide. des biens à lintérieur du cousinage. Appliquer à l'aristocratie du $x^{\mathrm{e}} \mathrm{s}$. une conception stricte de la propriété individuclle. identique à celle que connaissent de nos jours les sociétés européennes, serait, en effet, une vue de l'esprit. L'indivision patrimoniale est alors inextricablement mêlée au cousinage, dont les membres profitent ensemble des domaines que leur a transmis la génération précédente. Sur le plan juridique. en outre, les règles qui président à l'héritage et au régime matrimonial empêchent toute fixation des fortunes à l'intéricur d'une seule maisonnée. D'une part, le système successoral n'est pas encore strictement agnatique; il ne favorise pas le passage intégral du patrimoine du père au fils aîné. Les biens sont plutôt partagés de façon équitable entre tous les héritiers, y compris les filles ct cadets ou les cousins des lignées agnatiques ou cognatiques ${ }^{35}$. D'autre part, à l'occasion de son mariage, l'épouse reçoit un douaire des plus consistants de la part de son mari, qui lui cède la jouissance du tiers, voire de la moitié de son patrimoine ${ }^{36}$. Or, nous connaissons le prestige que la dame apporte à sa famille d'adoption et son rôle dans la préservation de la mémoire du cousinage. De plus, les biens qu'elle reçoit de son époux lui donnent un statut matériel enviable, surtout en cas de veuvage. Mais, plus important peut-être, la cession du douaire lui accorde un droit de regard sur l'ensemble des terres, des troupeaux et des trésors de la Sippe. Cette surveillance de la gestion de la richesse familiale est une source de pouvoir pour la dame du $\mathrm{X}^{\mathrm{e}}$ s., dont les sources attestent le degré de culture, la capacité de décision politique et l'influence sociale ${ }^{37}$.

Revenons au constat de la cohésion patrimoniale du cousinage, qui jouit en indivis de ses biens. Cette solidarité transparaît clairement dans la gestion collective des offices impériaux. devenus

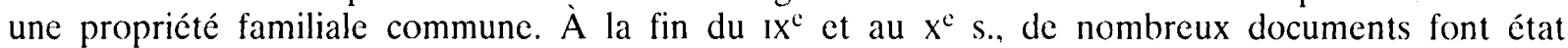
de deux ou trois frères, beaux-frères ou cousins qui agissent conjointement en tant que comtes de la même cité, ou qui se succèdent les uns aux autres à la tête de ces principautés au détriment de leurs propres fils. Dans les régions pyrénéennes, Guifred $\mathrm{I}^{\text {er }}$ le Velu $(\dagger 897)$ est comte de Cerdagne avec son frère Miró ${ }^{\text {er }}(\dagger 896)$ et comte de Besalú avec Radulf $(† 920)$, un autre de ses frères. Ce même Miró Ier transmet, à sa mort, le comté de Roussillon à Sunyer II ( $* 15)$, son cousin germain, qui régit alors le comté d'Empúries avec son frère Dela $(\dagger 894)$. À la génération suivante, Sunyer I ${ }^{\text {er }}(\dagger 947)$ succède à son frère Guifred II Borrell $(\dagger 911)$ aux comtés de Barcelone, Gérone et Vic ${ }^{38}$. C'est de façon solidaire, cohérente et concertée que ce cousinage administre les territoires de la marche avec l'islam, que Charles le Chauve leur a confiés. Une situation similaire se retrouve dans les pays du Bas Rhône, où les frères Boson (†966) et Guilhem I Ir font passer à Roubaud II $(+1008)$ et à Guilhem II $(† 993)$. fils de Boson, les comtés d'Arles et Avignon. qu'ils occupent en frérèche, et à partir desquels ils étendent leur pouvoir à la Provence tout entière ${ }^{3 \%}$. Ces cogouvernements fraternels et ces successions népotistes montrent l'intensité des liens qui unissent les membres de la Sippe, pour lesquels la primogéniture est loin d'être une valeur dominante. Aînés et puînés occupent ensemble les charges que leur transmet la génération précédente.

35. Ibid., p. 70, 260): - Scmuln). "The Structure" (voir n. 15). p. 47.

36. (h. Latranson-Rosaz. "Douaire et sponsalicimm durant le haut Moven Âge". dans Velues et veluage dans le Hau Moyen Âge. éd. M. Parisse. Paris. 1993. p. 99-106. et R. Le Jax. "Aux origines du douaire médiéval (17"- ${ }^{\circ}$ siècles)". ibid., p. 107-122: - A. LeFEBvre-Thin. ARD. Introduction historique au droit des personnes et de la famille. Paris. 1996. p. 151: - M. At:ktil.t. Lees noces (voir n. 32). p. 113-123.

37. Cf.. en dernier lieu. Pallakls, Mluara (voir n. 14). p. 107-134: - M. Al:kel.t. "La détérioration du statut de la femme aristocratique en Provence $\left(\mathrm{x}^{\circ}-\mathrm{x} \mathrm{xI}^{\circ}\right.$ s.) $)$. Moven Age. 91. 1985. p. 5-32

38. Al:ret.I. Les noces (voir n. 32). p. 44-46.

39. J.-P. Pory. La Provence et la société féodale (879-1166). Paris. 1976. p. 30-39: - G. de Maviever. La Provence du r' cut xir's., Paris. 1905, p. 209-234. 
Le cousinage apparaît, somme toute, comme une structure de parenté horizontale. sans réelle conscience dynastique ni profondeur généalogique, où les agnats et les cognats d’une même génération assument en indivis leur fortune et leur puissance. Il permet à des parentèles très étendues, liées à la famille royale, de conserver une identité commune autour d'un ancêtre plus ou moins mythique. Il pousse au voyage les familles, qui trouveront un point de chute auprès de leurs consanguins. Il privilégie les stratégies matrimoniales isogamiques ct endogamiques. Il accorde. enfin, une place de choix à la femme, détentrice d'un vaste patrimoine matériel, culturel et commémoratif.

\section{Lignage : agnatisme, sédentarité et primogéniture}

Le cousinage ne résiste pas à ce que les historiens appellent - n’ayons pas peur de l'expression. en dépit d'une polémique récente ${ }^{40}$ - la mutation de l'an mil. En tout état de cause, il est remplacé alors par le lignage, un autre système de parenté ${ }^{41}$, sclon des rythmes régionaux que la recherche actuelle s'efforce de préciser. Corollaire de l'effondrement du pouvoir royal. l'émergence de la principauté territoriale, puis de la châtellenie indépendante et de la seigneurie banale. entraîne de nombreux conflits entre les familles nobiliaires. Il s'ensuit une construction considérable de forteresses privées à vocation militaire et symbolique, autour desquelles s'étend un détroit ou district contrôlé par les gucrricrs qui y demeurent. Le rapport de la noblesse à l'espace s'est ainsi radicalement transformé ${ }^{42}$ : les aristocrates rétrécissent de façon considérable leur rayon d'action et abandonnent le nomadisme d'antan. Chaque famille se sédentarise dans le château, devenu son lieu d'attache, auquel elle associe parfois une chapelle castrale ou une fondation monastique, nécropole pour entretenir la mémoire des défunts de la maison et pour offrir des suffrages à leur intention ${ }^{43}$. En définitive, le cousinage éclate dans une multitude de maisons indépendantes. parfaitement localisées dans l'espace.

À l'opposé de la Sippe, le lignage s'organise d'après un schéma vertical, dynastique, où la filiation prime sur la consanguinité. La primogéniture, la transmission à l'aîné (senior) de l'essentiel du pouvoir régalien de coercition et de l'héritage. triomphe sur l'exercice indivis du pouvoir et sur la possession collective des domaines ${ }^{44}$. Lagnatisme, où priment l'ascendance et la descendance masculines, l'emporte désormais sur le cognatisme indifférencié. Sur ce point, les médiévistes ont fait remarquer l'ambiguïté du terme «lignage», le plus employé de nos jours pour désigner cette forme que prend la parenté en l'an mil : en ancien français, en effet, ce mot conserve une dimension matrilinéaire ${ }^{45}$, que nous lui avons enlevée; pour éviter cette confusion, certains historiens lui préfèrent donc le plus exact "patrilignage». Ancrage dans un château, cristallisation sur un domaine, succession centrée sur la primogéniture, pouvoir accru de l'aîné, patrilinéarité et agnatisme... Tels sont les traits constitutifs du lignage.

40. D. Barthíli:my, "la mutation féodale a-t-elle eu lieu? Note critique". Annales ESC, 47. 1992. p. 767-777. et "Fncore le débat de l'an mil!". Revue historique de droit françatis et étranger, 73, 1995. p. 349-360): - J.-P. P(ol.Y et F. Botrivazis. "Que faut-il préférer au mutationisme? ou le probleme du changement social». ibid.. 72. 1994. p. 401-412. et "Post-scriptum», ibid., 73, 1995. p. 361-362. (f. les contributions de Th. N. Bissox, D). Barthíl.emy, S. D. Whitr. T. Rilter. C. Wickinam. dans Past and Present, 142. 1994, 152. 1996. et 155. 1997.

41. "Dans les documents dons nous disposons. tout apparait comme si progressivement. aux différents degrés de laristocratic. les structures de parenté s'étaient transformées entre le début du $x^{c}$ et le milieu du $\mathrm{XI}^{\prime} \mathrm{s}$.". (j. D) D Hommes et structures du Moyen Age, Paris/La Haye. 1973. p. 283.

42. La littérature sur cette révolution castrale est abondante. Se reporter. en dernier lieu. au stimulant article dA. Dianord. "The Castellan Revolution and the Peace of God in Aquitanid". dans The Peace of (iod. ed. Th. Hean) et R. LANDES. Ithaca/Londres. 1992. p. 135-164.

43. F. Maginavi, Monasières et aristocratie en Provence (milieu $x^{4}$-début xit s.), Münster. 1999 (Vita regularis. 10): -

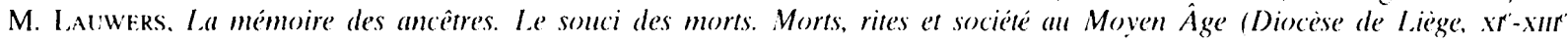
s.), Paris. 1997.

44. Sur la structure lignagère et l'association anticipée de l'héritier au sein même de la famille royale capétienne. cf. A. W. L.ewis. Le sang royal. La famille capétienne et l'Etat $\left(\mathrm{x}^{\prime}-\mathrm{x} \mathrm{N}^{\circ}\right.$ s.). Paris. 1986.

45. Dans l'Âtre périlléux (milicu xuI s.). Gauvain est ainsi donné comme appartenant au lignage de son oncle maternel

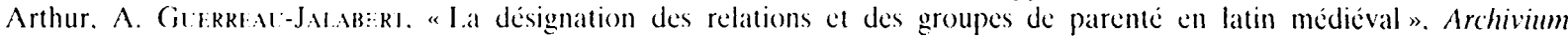
Latinitatis Medii Fvi, 46/7, 1988. p. 92. 
Il importe d'insister sur le contexte belliqueux où intervient cette mutation du système de parenté. L'éparpillement des prérogatives régaliennes jusqu'au niveau des châtellenies est à l'origine du lignage. L'aîné ou chef de la familia, maître de la forteresse. s’érige en chef d’une maison de guerriers qui combat ses voisins. Naguère, l'Empire carolingien concentrait. tant bien que mal, la puissance militaire entre les mains du roi et réprimait les manifestations privées de la violence: par la suite, les principautés territoriales assurent aux détenteurs de ce pouvoir régional une certaine mainmise sur les hommes et sur les institutions publiques. À la fin du $x^{\mathfrak{c}}$ et au début du $\mathrm{xl}^{\mathrm{e}}$ s., toutefois, le morcellement du ban entraîne l'individuation des maisons nobiliaires. qui s'arrogent le droit d'exercer la violence et qui se combattent les unes les autres. C'est alors par les armes que la famille apporte à chacun de ses membres une protection que l'État défaillant n'est plus à même d'assurer. Cette solidarité militaire est l'un des éléments clefs de la compréhension du lignage. Elle implique un encadrement, un étroit contrôle de ses membres, qui deviennent parfois étouffants. C'est alors qu'éclatent des conflits intrafamiliaux, déclenchés par la longévité du père qui retarde la transmission de l'héritage, par la trop forte emprise de la veuve qui empêche l'émancipation de l'aîné ou par le préjudicc porté aux intérêts des cadets. Ces luttes, au demeurant exceptionnelles, témoignent du trop plein de la cohésion lignagère.

Il est difficile de préciser la chronologie de l'avènement du lignage. En Provence, c'est à partir des années 1050, au cœur de la crise de fidélité qui distend les liens entre le comte et les grands, que les donateurs aristocratiques de Saint-Victor de Marseille figurent ensemble sous le mot de fratresca, groupe large de parents régi par l'aîné, dans les listes de souscripteurs des actes de son cartulaire : plus de la moitié des donations sont alors effectuées par ces groupes familiaux ${ }^{4 h}$. Cet exemple est significatif, car il intervient dans un contexte de révolte généralisée de la noblesse. L'identité familiale et la solidarité politique de ces lignages se cristallisent justement au moment même où ils récupèrent le ban qui échappe à la maison comtale. L'affaiblissement du prince renforce la famille. Avec Georges Duby, on peut donc affirmer que "l'histoire du lignage est une succession de contractions et de détentes, dont le rythme suit les modifications d'ordre politique ${ }^{47}$. En définitive, le resserrement de la parenté intervient dans la période trouble d'émiettement des pouvoir publics.

Dans un tel contexte, les étapes et formes de la genèse du lignage dépendent largement des réalités politiques de chaque principauté territoriale. De plus en plus, les historiens, conscients de cette diversité, s'efforcent d'affiner leurs analyses, tandis qu'ils décrivent ces variations régionales. Dans le Biterrois, l'évolution se fait de façon progressive. Claudie Duhamel-Amado y distingue deux étapes : "lignage arborescent», combinant structures patrilinéaires et matrilinéaires vers 1030-1100, puis "resserrement lignager", strictement agnatique, de 1100 à $1170^{48}$. Une étude en cours sur les familles de Durfort, de Cabaret et de Termes, en Haut-Languedoc, tendrait à montrer que chacune d'entre elles adopte, aux $\mathrm{XI}^{\mathrm{e}}$ et $\mathrm{XII}^{\mathrm{e}}$ s.. une organisation différente : cousinage, fratrie et lignage ${ }^{49}$. En Piémont, la contraction familiale intervient tôt dans le $x^{\mathfrak{e}} \mathrm{s}$; elle aboutit, au lendemain de l'an mil, aux consorterie, regroupements de lignages, unis par un serment de parentela et societas ${ }^{50}$. En Poitou, la primogéniture s'impose largement parmi les vicomtes et châtelains, bien que la succession de frère à frère ou droit de viage subsiste. en particulier dans les grandes familles de Thouars ou Mauléon ${ }^{51}$. Pour la Catalogne, enfin, José Enrique Ruiz-Doménec insiste sur les "sous-lignages", branches cadettes, issues d'une souche principale qui en encadre les

46. M. Alket.l. "I.e lignage aristocratique en Provence au xi" s. ". Annales du Midi, 98. 1986. p. $149-163$.

47. La société ana xr et xur s. dans la régionn mâconnaise, 20 éd.. Paris. 1971. p. 122.

48. La famille aristocratique languedocienne : parenté et patrimoine dans les vicomtés de Béaiers et d'Agde 190()-ll70) |thèse d'État inédite de l'Université de Paris IV]. 1995. p. 525-604.

49. G. Iavions, "Diversité des pratiques familiales et patrimoniales. I. exemple de quelques familles aristoeratiques

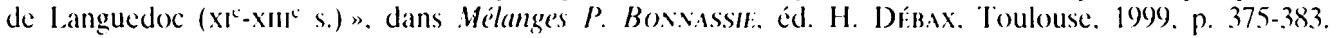

50. G. TAвAссо. " I.e rapport de parenté comme instrument de domination consortiale : quelques exemples piémontais ". dans Famille et parenté (voir n. 8). p. 153-158.

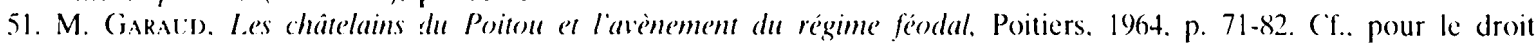

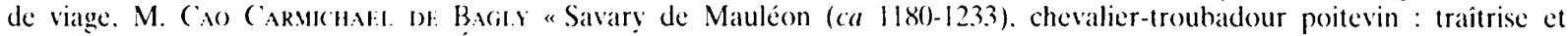
société aristocratique ". L.e Mopen Áge. 105. 1999. p. 269-306. 
membres, toujours prêts à guerroyer à son service ${ }^{52}$. Encore au $\mathrm{XII}^{\mathrm{c}} \mathrm{s}$., le cousinage est de mise dans les familles comtales castillano-léonaises : le système wisigothique de partage égalitaire des biens entre les enfants prévaut: les femmes et les collatéraux exercent un droit de regard sur le patrimoine familial; la forte emprise royale empêche la formation de lignages trop rigides, solidaires et puissants ${ }^{53}$. Ces différents modèles, établis d'après une analyse serrée des sources locales, décrivent dans toutes leurs nuances les formes multiples et changeantes de la nouvelle structure de parenté.

L'avènement du lignage coïncide, en outre, avec une véritable révolution anthroponymique. Lc système onomastique propre au cousinage, reposant sur une dénomination unique, se transforme. Au nominatif, au génitif ou par la préposition de, un patronyme familial est désormais accolé au nom personnel. Presque toujours, ce deuxième élément rattache son porteur à la principale seigneurie du lignage. Entre 1080 et 1100 , vingt-quatre de ces trente et un surnoms en usage dans la noblesse mâconnaise reprennent le toponyme d'un domaine foncier de la famille; les sept autres seulement sont des sobriquets devenus héréditaires ${ }^{54}$. Au sein de la noblesse, le nouveau patronymc traduit le profond enracinement de chaque lignage dans un château et son arrière-pays. Au milieu du $\mathrm{XII}^{\mathrm{e}}$ s., il est lié à l'apparition d'armoiries, pour la plupart parlantes (se rapportant au nom de famille), et au rattachement de certaines maisons à des héros épiques 55 . Autre évolution tardive de ce modèle culturel aussi prestigieux qu'utile pour rattacher un individu à sa famille : le patronyme est adopté par toutes les catégories de la société à l'imitation de la noblesse ${ }^{56}$.

Tout comme la nouvelle dénomination à deux éléments, la genèse du lignage patrilinéaire affecte le choix des noms de baptême, dont le nombre se réduit pour chaque maison. L'habitude s'instaure ainsi de transmettre à l'aîné le nom de son père ou de son grand-père paternel : celui qu'on choisit pour l'enfant contient un véritable programme de vie, un rappel de la fonction à exercer ${ }^{57}$, et il est normal que le futur chef de famille reproduise le modèle paternel. Le deuxième fils reçoit, de même, un nom agnatique. En revanche, les cadets prennent des noms tirés de la parenté maternelle, qui reste comme par le passé prestigieuse. Ces nouvelles règles, fondées sur la primogéniture et sur l'apparition du patronyme, appauvrissent le stock onomastique masculin : Guillaume, Raimond, Hugues ou Geoffroi reviennent sans cesse dans les chartriers et cartulaires $\mathrm{du} \mathrm{XI}^{\mathbb{C}}$ s. La palette anthroponymique est, cependant, beaucoup plus riche pour les filles, dont le nom est octroyé dans la liberté et l'imagination : on évite de la sorte l'homonymie, et il est rare que les scribes des chartes aient recours au deuxième élément pour désigner une femme ${ }^{58}$. Des doublets permettent, par ailleurs, de rappeler leurs origines lignagères : on trouve ainsi dans l'aristocratie provençale des Bautugate de Baux, des Sacristane Sacristain et des Porcelette Porcelet ${ }^{59}$. De nouveaux courants religieux peuvent, enfin, accrôtre le nombre de noms donnés sur les fonts baptismaux : le succès de Pierre et de son féminin Pétronille traduit peut-être le prestige retrouvé du Saint-Siège au lendemain de la réforme dite grégorienne. La chanson épique et sa fascination pour les héros des matières de France, de Rome et de Bretagne influencent également l'anthroponymie : à la fin du $\mathrm{xI}^{\mathfrak{C}}$ s., parmi les seigneurs des villages du Latium, on trouve

52. "Système de parenté" (voir n. 6). p. 314.

53. S. BARToN. The Aristocracy in Twelfth-Century Leon and Castile. Cambridge, 1997.

54. Dubr. Hommes (voir n. 41). p. 397.

55. F. MAzr:I., "Memoire héritee. mémoire inventé : Guilhem de Baux, prince d'Orange. et la légende de (juillaume

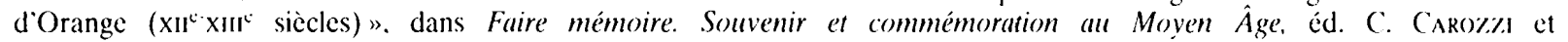
H. Taviani-Cakozizi. Aix. 1999. p. 193-228.

56. Cf. les quatre volumes Genèse médiévale de l'anthroponymie moderne. éd. M. Botrix. Tours. 1989/97.

57. K. F. Wfrner. "Lien de parenté et noms de personne : un problème historique et méthodologique », dans Famille et parenté (voir n. 8). p. 28.

58. Outre l'introduction de M. Bourin au volume II-2 (voir n. 56). consacré à l'anthroponymie féminine. cf. M. Zimmermavis. "I.es débuts de la "révolution anthroponymique" en Catalogne ( $\mathrm{x}^{\circ}$-xir" siècles)". Anmales du Midi, 102. 1990. p. 301.

59. M. Aurs:1.1. Une famille de la noblesse provençale au Moyen Áge : les Porcelet, Avignon. 1986. p. 57. 
des Charles, Pépin, Roger, Roland, Olivier, Ogier, Alexandre ou Achille 60. Règles successorales et modes éphémères déterminent les choix anthroponymiques dans la dénomination de l'aristocratie. La primogéniture, qui bloque le stock onomastique patrilinéaire au profit de l'aîné, entraîne d'autres conséquences. Grâce à elle, le lignage peut se passer de la restriction de la nuptialité ou d'un quelconque contrôle de naissances ${ }^{61}$. A sa suite, de nombreux puînés apparaissent comme les laissés-pour-compte des structures lignagères alors que le premier né se taille la part du lion dans le patrimoine familial 62 : la littérature se fait l'écho de cet antagonisme intrafamilial, tandis qu'elle présente sous un jour négatif l'aîné, qui lèse les intérêts de ses frères, et qu'elle exalte la gémellité sans hiérarchie ${ }^{6.3}$. Les cadets se regroupent dans des bandes armées de "jeunes" (juvenes), mot qui recouvre davantage l'état de célibataire qu'une classe d'âge. Ils courent le pays en quête de gloire et de fortune, détroussant les marchands, volant les paysans ou combattant à la solde d'un châtelain. L'obtention de butin soude ces compagnies de guerriers déprédateurs, qui le partagent et le gaspillent ensemble ${ }^{64}$. Ce trop plein d'agressivité juvénile est canalisé vers de lointaines guerres de conquête, au premier rang desquelles il faut placer la croisade, aboutissement logique du mouvement de la Paix de Dieu 65. Mais la Terre sainte n'est pas la seule destination de ces cadets en mal d'héritage. Orderic Vital rapporte comment, au début du $\mathrm{XI}^{\mathrm{C}} \mathrm{s}$., Tancrède de Hauteville, à qui ses deux épouses avaient donné douze fils et plusieurs filles, après avoir cédé son patrimoine dans le Cotentin à son aîné Geoffroi, "conseilla aux autres garçons de trouver leurs voies par la force et l'esprit en dehors de leur pays d'origine ${ }^{66}$ »; ils partirent pour l'Italie du Sud, devenant la souche des dynasties princières de Sicile et ensuite d'Antioche ${ }^{67}$. Les exemples de cette émigration de juvenes pourraient être multipliés. Au fond, leur objectif est de se caser, de se ranger, d'épouser une riche héritière qui leur apporte un domaine et des enfants, afin de constituer leur propre lignage. En attendant, ils écoutent avec plaisir les nouvelles sur la recreantise, la couardise, d'Érec, ou la jalousie sauvage d'Archambaut de Bourbon, vices dont ils sont devenus la proie justement à l'occasion de leur mariage 68 . En dénigrant l'état matrimonial, les cadets disent toutes leurs frustrations et toute leur envie pour le sort de l'aîné, accapareur d'héritages.

Il ne semble pas qu'il faille réduire le modèle lignager à la seule aristocratic. Du moins la famille paysanne connaît-elle des transformations similaires au lendemain de l'an mil. C'est la thèse qu'a récemment soutenue Lluís To pour la Catalogne ${ }^{69}$. Autour de 1030, la maison paysanne et les terres qui en dépendent (mansum) deviennent le lieu par excellence de la perception de nouvelles taxes seigneuriales. Les cultivateurs se transforment en ammassati et affocati, assignés à résidence dans un manse ou dans un foyer. Ils sont désormais attachés à la glc̀be et tout départ vers Ic front pionnier de la reconquête leur est interdit, sauf s'ils paient un droit exorbitant, la remença (de remanere, "demeurer "). " Hommes propres et exclusifs" du seigneur, ils subissent un contrôle serré sur leur mariage et sur leur succession : ils versent désormais le formariage et la main-morte ${ }^{70}$. Comme dans le droit des fiefs, la tenure, unité d'imposition, ne saurait plus être partagée, divisée, morcelée. La primogéniture est donc imposée à la paysannerie entre 1050 et 1150 . Elle implique la «famille souche»par laquelle le premier né (hereu, pubilla), marié et avec enfants, cohabite avec ses parents dans la maison dont il héritera un jour. alors qu'auparavant seul le ménage et

60. P. Toubert. Les structures du Latium médiéval. Le Latium méridional et la Sabine du ix' siécle à la fin du xir' siecle, Rome/Paris. 1973, p. 698.

61. Atriti.. "Le lignage" (voir n. 46). p. 155-156.

62. Sur les pouvoirs de discipline exercés par l'ainé au for interne familial et sur l'échec social des cadets. cf. TotbBl:RT.

les structures (voir n. 60). p. 737 et p. 767.

63. Séminaire de D. Reigner-Bohler au C.F́.S.C.M. de Poitiers, le 14 septembre 1994.

64. Duby. Hommes (voir n. 41). p. 213-225.

65. Le concile de Clermont de 1095 a la croisade. Actes du colloque universitaire international de Clermont-Ferrand (2.3-25 juin 1995), Rome. 1997.

66. The Ecclesiastical History, éd. M. ('hiswal.1. (Oxford. 1969/75, t. 2. p. 99.

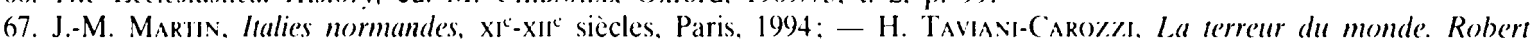
Guiscard et la conquête normande en Italie. Paris. 1996.

68. Séminaire de G. Gouiran au C.É.S.C.M., en février 1995.

69. I. To Folditras. Familia $i$ hereu a la Catalunya Nord-Oriental (segles X-XII). Barcelone. 1997.

70. P. Frefidmax. The Origins of Peasam Servitude in Medieral Catalonia, Cambridge, 1991. 
sa progéniture vivaient sous le même toit. La paysanneric a, en définitive, connu un avatar du resserrement lignager de l'aristocratic.

Le passage du cousinage au lignage transforme les pratiques matrimoniales de la noblesse. Il semblerait que l'étroite endogamie et l'isogamie, qui assuraient la cohésion des consanguins et des princes territoriaux de la Sippe du $\mathrm{x}^{\mathrm{e}}$ s., tendent à s'atténuer ${ }^{71}$. Quoi qu'il en soit, le choix d'une épouse répond à de nouveaux impératifs politiques et militaires : les guerres privées entre châtelains voisins conditionnent au jour le jour les alliances matrimoniales de l'aristocratie. Le Conventum, récit rapportant les luttes nobiliaires du Poitou vers 1030, s'ouvre par la promesse d'Hugues le Chiliarque de Lusignan $(\dagger 1032)$ d'épouser la fille du vicomte de Thouars en échange des biens de Boson de Châtellerault; Guillaume V (993-1030), duc d'Aquitaine, ne veut pas de cette union huppée qui risque de lui porter ombrage, et il impose à Hugues la veuve de son allié Joscelin, châtelain de Parthenay, dont l'héritage est bien plus modeste. La rupture des fiançailles, déterminée par ce renversement d'alliance, est un grave affront qui doit être vengé par les armes. Il s'ensuit des luttes locales que l'auteur anonyme de ce texte présente sous un jour épique 72. Cette histoire est significative des enjeux de la politique matrimoniale dans un contexte belliqueux ${ }^{73}$. Le mariage est bel et bien "alliance", au sens anthropologique du terme : il sert à créer des liens et à établir des pactes entre deux groupes de parenté. Qu'il soit utilitaire, pour les biens matériels et le réseau de clientèles qu'il apporte, ou prestigieux, pour sa valeur symbolique, il répond à des stratégies visant à augmenter le pouvoir de chaque lignage.

Ces calculs politiques fragilisent souvent, comme dans le Conventum, les fiançailles, trop dépendantes d'une tactique aléatoire. Il en va de même pour les mariages, rompus parfois à la suite d'un retournement politique. De la même façon, la stérilité supposée de l'épouse constitue une excuse facile pour la renvoyer. Par leurs divorces et remariages à répétition, les nobles s'adonnent à une polygamie successive, sérielle, mais ils s'accommodent aussi bien d'une polygamie simultanée ${ }^{74}$. Jusqu'à la fin $\mathrm{du}_{\mathrm{XI}^{\mathfrak{c}}}$ s., la dynastie normande fait coexister un mariage more franco, contracté pour des raisons exclusivement politiques, rarement fertile, avec une union more danico, qui rend la concubine mère des ducs ${ }^{75}$. Cette bigamie dissocie, par conséquent, l'alliance officielle, contractée à la suite d'un traité passé avec les princes environnants, de la cohabitation féconde où le duc s'est choisi pour compagne une jeune fille d'origine sociale inférieure, qu'elle ait été capturée à l'occasion d'un raid en Bretagne, exigée d'un pelletier de Falaise ou demandée à une famille de la noblesse du pays de Caux ${ }^{76}$. En Flandre, Lambert d'Ardres, chapelain et chroniqueur des comtes de Guines, évoque les égarements de son maître Baudouin II (†1169), «qui corrompit plus de vierges que David, Salomon et Jupiter ", devenant le père d'au moins vingt-trois bâtards 77 . Faire ostentation de sa puissance, s'assurer une descendance et obtenir de nombreuses alliances déterminent la polygynie aristocratique.

Au lendemain de l'an mil, l'hypergamie, par laquelle l'homme prend une épouse de rang supérieur au sien, est largement répandue dans la noblesse. Elle permet au châtelain de marier sa fille à l'un des guerriers de son entourage, dont il affermit du coup la loyauté. En contrepartie, le jeune marić obtient une alliance prestigieuse qui facilite son ascension sociale. Quelques monographies

71. Aurril.. Les noces (voir n. 32). p. 44-81

72. Le "Conventum" (vers 1030). Un précurseur aquitain des premières épopées, éd. G. Bfach. Y. (hativin et G. Pon, Genève. 1995.

73. I.e contrôle par le pouvoir princier du mariage de laristocratie est bien plus efficace en Normandie où. par exemple. Guillaume le Bâtard donne. au lendemain de Hastings (1066) les femmes de laristocratic anglo-saxonne aux conquérants normands de son entourage. D. L f:Tr. "L.es épouses dans l'aristocratie anglo-normande des XI' ${ }^{\circ} I^{\circ}$ siècles". dans l.e mariage au Moven Âge, éd. J. Tryssor. Clermont-Ferrand. 1997, p. 20.

74. Sur le rôle des bâtards. placés "en contrebas des fils légitimes. mais tout de même en réserve du lignage ". cf. D. Bakthíli:my, La société (voir n. 10). p. 539.

75. Pour L. Musset, il s’agit d’un "concubinat légal sans bénédiction ecclésiastique, assurant aux enfants qui en étaient issus la pleine capacité successorale". "Les apports scandinaves dans le plus ancien droit normand". dans Mélanges J. YVIR. Rouen. 1976. p. 560).

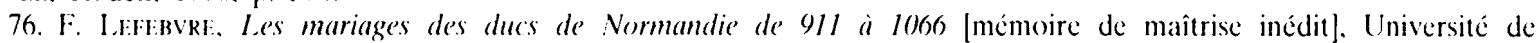
Rouen. 1991

77. Historia comitum Ghisnensium, MGH. SS, 1879, t. 24. p. 557-642. 
montrent combien ces unions peuvent hisser la famille d'un homme de second rang au sommet de la hiérarchie aristocratique. Ives, premier membre connu des Nesle, une des plus importantes maisons picardes, fait irruption en 1085 dans l'entourage du roi Philippe Ier, alors quaucun de ses ascendants n'a jamais fréquenté la cour royale; sa réussite s'explique par ses noces avec une femme de haute extraction, fille du comte d'Eu et de la comtesse de Soissons: en 1141. leur petit-fils héritera du Soissonnais 78 . En 1117, le mariage entre le sénéchal Guillem Ramon et Beatriu de Montcada, détentrice du château qui contrôle l'accès septentrional à la ville de Barcelone, est de la même nature : les enfants issus de cette union - qui portent de façon significative le nom de Montcada, celui du domaine maternel - fondent la plus puissante des lignées aristocratiques catalanes, qui occupera un jour la vicomté de Béarn ${ }^{79}$. La fiction littéraire conserve des traces de ces mariages hypergamiques, qui fondent le succès durable d'une dynastie. Bien des écrits généalogiques de la fin du $\mathrm{XII}^{\mathrm{e}} \mathrm{s}$. font d'un aventurier l'ancêtre mythique des maisons princières ou aristocratiques : il s'agit presque toujours d'un jeunc en quête de fortune et de renommée dans un inlassable voyage, parti de rien, mais gagnant par ses hauts faits d'armes une riche héritière, qui lui apporte les terres où se perpétue leur longue descendance ${ }^{80}$. Pourvu qu'il soit chevaleresque, le modèle de l'homme nouveau. bâtissant à la force du poignet une maison nobiliaire, ne dérange nullement les vieilles dynasties, conscientes de la diffusion de telles stratégies matrimoniales.

L'hypcrgamic donne lieu à ce que les ethnologues appellent un «système dissymétrique » d'alliance ou d'«échange indirect" de femmes, au terme duquel un groupe tribal donne des épouses à un autre qui en cède, à son tour, à un troisième. À quelques nuances près, ce schéma a été appliqué avec succès à des régions de l'an mil, qui, comme le comté de Barcelone, conservent suffisamment de chartes pour établir de nombreux tableaux de filiation : les vicomtes de cette ville épousent des femmes d'origine comtale et donnent leurs filles à des viguiers qui, à leur tour, s'attachent comme gendres les chevaliers de leur forteresse ${ }^{81}$. De la sorte, l'hypergamie est liée à un phénomène largement attesté au $\mathrm{XI}^{\mathrm{C}} \mathrm{s}$. : la montée des milites, chevaliers issus parfois du milieu des alleutiers ou paysans libres, voire même de la servitude, qui mettent leur savoir militaire au service d'un grand ${ }^{82}$. La mobilité sociale dépend, en grande partie, de ces stratégies matrimoniales. Il n'empêche qu'elles peuvent encourager aussi l'endogamie, en figeant la structure sociale. L'hypergamie favorise, en effet, l'union entre "cousins croisés» (enfants d'un frère et d'une søur par opposition aux "cousins parallèles", nés de deux frères ou de deux sœurs). Génération après génération, l'« échange généralisé " ou "dissymétrique " fait que les nobles épousent des femmes de leur belle-famille. Ces alliances consanguines ont été analysées de façon pénétrante par Anita Guerreau-Jalabert, qui montre la fréquence des unions autour du cinquième degré du comput canon et les "bouclages consanguins" qu'elles entraînent. Elle insiste, de même, sur le "redoublement d'alliance " à la même génération, qu'on retrouve dans le mariage de deux frères à deux sœurs ou d'un frère et une sæur à une sœur et un frère ${ }^{83}$. Cette dernière stratégie renvoie à la notion d' "échange restreint » ou "symétrique », par lequel deux groupes de parenté sont réciproquement donneurs et preneurs de femmes.

L'hypergamie a pour autre conséquence l'avunculat, la relation privilégiée entre le neveu et l'oncle maternel, souvent vassal et fidèle. C'est ainsi dans le châtcau de son avunculus, supérieur en

78. W. M. Newmax, Les seigneurs de Nesle en Picardie (xIr-xirt' siecle), Paris. 1971, p. 23.

79. Le pouvoir que ce mariage apporte à (juillem Ramon est tel que le comte de Barcelone Raimond Bérenger IV exigera du couple la séparation. apres vingt ans de vie commune. J. C. Sulditir. A Medieval Catalan Noble Family: The Montcudas, 1000)-1203. Berkeley, 1983.

80. F. Bot:r.vazi:1. "Mémoire et parenté ". dans La France de l'an mil, éd. R. Detorio Paris. 1990, p. 114-124.

81. J. E. Ri:r-Dominfe. "Systime" (voir n. 6): L'estructura feudal: sistema de parentiu i teoria de ladiança en la societat catalana (c. 980-c. 1220). Barcelone. 1985: - et B. Garí. El linaje de los Castellvell én los siglos XI y XII. Bellaterra (Barcelone). 1985.

82. (f. J. Forort. Chetaliers et chevalerie au Moven Âge, Paris. 1998. p. 64-88. et en dernier lieu "I exilogie et société : la dénomination des milités normands d’talie che\% (ieoffroy Malaterra". dans Mélangés P. Boxidssst: (voir n. 49). p. 271-278.

83. A. (itrkRtal-Jalablert. "Prohibitions canoniqués el stratégies matrimoniales dans laaristocratie médiévale de la

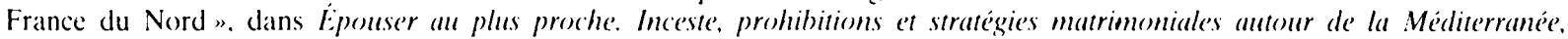
éd. P. Bovil. Paris. 1994. p. 293-321. 
pouvoir et fortune au père, que l'enfant fait son éducation militaire. Quand, devenu adolescent, il devient son fidèle et il lui prête la foi et l'hommage, il rappelle de façon rituelle le nom de sa mère qui est précisément celui de la sœur ou de la tante de ce même seigneur ${ }^{84}$. La fiction traduit également la relation avunculaire. Dans les chansons de geste ou les romans courtois, les fils déçoivent souvent leur père : ils sont remplacés auprès de lui par ses nevcux, beaucoup plus proches, qui lui vouent une affection particulière. Charlemagne et Roland, Arthur et Gauvain, Marc et Tristan sont autant de couples oncle-neveu qui révèlent la répercussion de l'avunculat dans l'imaginaire nobiliaire ${ }^{85}$.

Dans le cadre de l'hypergamie, les jeunes guerriers paient au prix fort l'alliance prestigieuse qui facilite leur ascension sociale. À l'époque encore, le régime patrimonial entre époux est régi par le versement d'un douaire, c'est-à-dire la cession par le marié à l'épouse de l'usufruit de la moitié ou du tiers de ses propriétés. Ces biens, que les législations germaniques du haut moyen âge appelaient le "Prix-de-la-mariée ", servent à "acheter " une femme qui appartient à un milieu social plus élevé que l'époux. En contrepartie de ces terres, troupeaux ou trésors, elle lui apporte le prestige et la renommée de sa maison d'origine, le regard admiratif que les autres aristocrates jettent sur son groupe de parenté, mais aussi l'ancienneté de sa maison : la noblesse en somme. La femme fournit ainsi un capital symbolique en échange d'un capital matériel. Dans le cadre de ces dons et contre-dons, les richesses circulent du bas vers le haut de la pyramide sociale, tandis que l'honneur est distribué dans un sens descendant 86 . Fnfin, ce douaire comprend les biens périphériques au noyau essentiel du patrimoine familial que le chef de lignage peut, le cas échéant, céder aux établissements ecclésiastiques. La femme devient donc protectrice des églises, auxquelles elle cède des terres prises sur cette dotation maritale ${ }^{87}$.

Par son douaire et par la supériorité du rang de sa famille sur celle du mari, la dame de l'an mil connaît un statut favorable au sein du couple. Elle profite d'une certaine autonomie économique. Mariée et surtout veuve, elle est respectée dans son pouvoir et ses biens. Les chroniques lui accordent un pouvoir informel, séduction qui lui permet d'influencer les décisions de son mari. Les chartes dressent le procès-verbal de la foi et l'hommage que lui prêtent ses fidèles. Sa condition, vestige du cousinage cognatique, est encore avantageuse. Toutefois, comme pour les cadets, elle commence à se dégrader en raison du pouvoir accru de l'aîné. La primogéniture et la militarisation de l'aristocratie rendent compte de cette détérioration du statut de la femme.

Le lignage est, en définitive, une nouvelle façon d'organiser la filiation : il se fonde sur la patrilinéarité et l'agnatisme; il accorde de larges pouvoirs à l'aîné; il déclasse les cadets; il centre chaque maison nobiliaire sur un château et son détroit; il provoque des guerres innombrables entre les différentes lignées. Il marque puissamment les mentalités nobiliaires par la conscience généalogique qu’il apporte à chaque maison aristocratique. Mais il comporte aussi un agencement

84. Exemple de seigneur et fidèle comme cousins : convenio tibi consanguineo et homine meo, charte catalane du début du XII" s. citée par B. Gakí, "Las querimonice feudales en la documentación catalana del siglo XII (1131-1178)". Medievalia, 5, 1984. p. 10. Sans être un serment de fidélité, cf. également le vocabulaire du traité d'Agreda par lequel Alphonse II d'Aragon se soumet, le 27 septembre 1162, à Ferdinand II. son beau-frère : Ego Fernandus (...) convenio (...) vobis consanguineo meo Ildefonso (...) qui meam sororem ducitis in uxorem... Ego Idefonsus (...) convenio vobis Fernando (...) consanguineo et sororio meo, quem loco patris tutorem ac defensorem meum et terre mee suscepi, J. E. Ruiz-DoménfC, "Estrategias matrimoniales y sistemas de alianzas entre Castilla y Cataluña en el siglo XII". Hispania, 40. 1980, p. 271-284.

85. D. RÉGnier-Bohler. "Fictions », dans G. Duby et Ph. Ariès. Histoire de la vie privée, Paris, 1985, t. 2. p. 336-338. L'amour pour la femme de l'oncle (Modred pour Guenièvre ou Tristan pour Iscult) est. en conséquence. l'une des plus graves transgressions. R. Bf.7zol.A. Les origines et la formation de la littérature courtoise en Occident (500-1200), Paris, 1966/68. t. 3. p. 157.

86. Ces problèmes ont été abordés dans le colloque Les transferts patrimoniaux durant le haut moyen âge : Morgengabe. dos, tertia... et les autres, qui s'est déroulé à Valenciennes du 2 au 4 mars 2000).

87. Pour le nord de la France carolingienne et capétienne, et plus particulierement pour Gerberge, ecclesiarum amatrix, femme de Louis IV, cf. J. Veridon. "Les sources de l'histoire de la femme en Occident aux X'-xII" s. ". Cahiers de civilisation médiévale, 19, 1977. p. 241-242. Sur ce point, le cas le plus spectaculaire est celui de la comtesse Sancha Muñiz. assassinée vers 1045 par ses neveux. en raison des legs trop généreux quelle a accordés à la cathédrale de León. P. Martínez Sopena. "Relations de parenté el héritage wisigothique dans l'aristocratie du rovaume de León au xi" s. ». dans L'Europe héritière de l'Espagne wisigothique, éd. J. Fontaine et Ch. Pilli.lstrandi, Madrid. 1992, p. 324. 
original de l'alliance : il encourage l'hypergamic; il incite au divorce, au remariage et aux autres formes de polygamie; il favorise l'avunculat. Les doctrines et pratiques cléricales bouleversent cependant la logique interne de ces stratégies matrimoniales.

\section{Alliance : consentement, exogamie et rituels}

Tout au long du haut moyen âge, l'Église propose un modèle matrimonial en accord avec l'enseignement évangélique et patristique. Ses postulats - en particulier l'indissolubilité et l'unicité - s'inscrivent en faux vis-à-vis de pratiques profondément enracinées dans l'aristocratie ${ }^{88}$. Ces comportements nobiliaires sont contestés avec force à l'époque carolingienne et surtout à partir des années 1050, dans le cadre de la réforme romaine, vaste offensive visant à changer les mœurs des clercs, mais aussi des laïcs ${ }^{89}$. Dans ce long conflit qui les oppose aux aristocrates, les prêtres disposent d'un atout considérable. Depuis le $\mathrm{IX}^{\mathfrak{C}}$ s., les tribunaux épiscopaux se saisissent des affaires matrimoniales au détriment des la justice royale ou comtale. Leur compétence en cas de conflit de juridiction est assurée par un serment que doivent prêter les futurs époux. Ce sont donc les juges ecclésiastiques qui décident sur la validité ou la nullité d'un mariage, sur la séparation de corps ou de biens, voire sur le douaire ou sur l'adultère ${ }^{90}$. Au lendemain de l'an mil, la crise des institutions publiques aidant, l'Église conquiert l'exclusivité de la justice en matière matrimoniale.

Sa doctrine sur la nature du lien conjugal se précise. Les théologiens affirment que le libre consentement des deux contractants est nécessaire pour établir la légitimité du mariage. Ils exposent ainsi sans ambages la théorie de l'autonomie de la volonté de la femme. Le pape Nicolas I ${ }^{\text {er }}$ (858-867) et l'archevêque Hincmar de Reims la formulent à l'occasion des procès en nullité des mariages de la famille carolingienne ou des décrétales pontificales. À l'époque, les penseurs développent la théorie de la fides, la confiance et la fidélité réciproque des époux, qui est à la base de ce consensualisme 91. L'un des premiers exemples de l'application du principe se trouve dans les Décrétales (1142) de Gratien : il met en scène Urbain II (1088-1099) s'opposant au roi Sancho Ramírez d'Aragon et Navarre (1063-1094), qui veut obliger sa nièce à épouser contre son gré l'un de ses chevaliers. En 1114, le biographe de saint Arnoul écrit au sujet de la fille du châtelain de Coucy : "L'autorité canonique prescrit de ne pas unir une jeune fille à quelqu'un dont elle ne veut pas ${ }^{92}$. "L'idée que le mariage doit être libre et intériorisé, créant entre les conjoints un lien déterminé par la charité, vertu qui croît en raison de ce choix même, est à l'origine de cette position ${ }^{93}$. Au $\mathrm{XII}^{\mathrm{e}}$ s., les plus audacieux des théologiens, comme Hugues de Saint-Victor $(† 1141)$ iront jusqu’à considérer que si les mariés ont librement exprimé leur volonté, leur union est valide, même si elle n'a jamais été consommée. Ces assertions minent l'autorité du chef de lignage qui entend utiliser selon son bon vouloir les stratégies matrimoniales pour augmenter la puissance et la richesse de sa maison. Elles sont révolutionnaires.

Elles se fondent sur un discours positif à l'égard du mariage et de l'amour conjugal ${ }^{94}$. Les textes cléricaux qui abondent dans le sens d'une théologie favorable à la vie matrimoniale sont largement

88. La dualité des modèles matrimoniaux - «morale des prêtres. morale des guerriers", p. 27-59 - est le fil conducteur de l'ouvrage de G. Dubr. Le chevalier, la femme et le prêtre, Paris, 1981. (f., plus récemment. M. Rotchis. "Des mariages païens au mariage chrétien". dans Segni e riti nella Chiesa altomedievale occidentale. Spolète. 1987. p. 835-880. et le colloque sur Sexualité et mariage au Moven Âge, que ce chercheur à organisé à Conques du 15 au 18 octobre 1998 [Actes sous presse].

89. "L'Église de la réforme grégorinne et "post-grégorienne" ne s'est pas contentée de faire la chasse aux prêtres concubinaires. Flle a condamné, on l'oublie trop souvent, tous les concubinaires ». Toublekt. Les structures (voir n. 60)). p. 730).

90. A. Fsmbis, Le mariage en droit canonique, Paris. 1891, t. 2. p. 17-32.

91. P. Tot:Bl:RT. «L La théorie du mariage chez les moralistes carolingiens ". dans /l matrimonio nella societa altomedievale, Spolète. 1977. t. I. p. 233-282. et "L institution du mariage chrétien de l'Antiquité tardive à l'an mil ». à paraître dans les Actes du colloque Morfologie sociali é culturali in Europa, Spoleto, 3-9 aprile 1997.

92. D. Barthél.timy, "Parenté ". dans Histoire de la vie privée (voir n. 85). t. 2. p. 1.31.

93. M.M. Shefmax, "(hoice of Marriage Partner in the Middle Ages: Development and Mode of Application of a Theory of Marriage". Studies in Medieval and Renaissance History. n.s.. 11. 1978, p. 1-33.

94. J. Lecclerco. Le mariage vu par les moines au xir's., Paris. 1982. el L'amour viu par les moines au xir's., Paris. 1983. 
plus nombreux que ceux qui la dénigrent. Prenons l'exemple d'une chronique, document dont le but premier n'est pas d'exalter. ni même pas d'aborder, le statut des mariés. Celle de l'évêque Thietmar de Mersebourg (975-1018) insiste sur le bienfaits religieux du mariage, qui découlent de l'engagement librement contracté par les époux. Cet état est compatible avec l'exercice du bien et de l'amour de Dieu : plus encore, il crée une communauté spirituelle où se développe la vie de la grâce ${ }^{95}$. Une telle perception du couple s'accompagne de l'insistance sur la mission de la femme, qui doit surveiller la moralité de son mari et de ses enfants, et accroître leur engagement chrétien ${ }^{\%}$. Devenue veuve, elle veille sur l'âme du conjoint défunt et elle offre des suffrages qui perpétuent, dans un cadre chrétien, son rôle traditionnel de détentrice de la mémoire familiale ${ }^{97}$. Une bienveillance identique pour le couple et la femme mariée se retrouve dans la facilité avec laquelle les métaphores nuptiales viennent sous le calame des scribes monastiques : une donation à un lieu de culte est inscrite dans une "charte dotale", car c'est bien un douaire cédé pour une église promise au Christ; au lendemain de la mort de l'évêque, dont l'anneau symbolise le mariage avec son Église, le siège épiscopal est "veuf »... ${ }^{98}$. Les images matrimoniales s'imposent dans la définition de l'Église, dégagée de toute simonie, infidélité redoutable dont il faut protéger l'épouse du Christ ${ }^{99}$. L'action du clergé sur les laïcs connaît une certaine réciprocité.

Les théologiens et canonistes condamnent la polygamie et le divorce avec davantage de détermination que les noces contraintes et forcées. A l'instar de l'union entre le Christ et l'Église, le mariage doit être unique et indissoluble ${ }^{100}$. Les répudiations, courantes en cas de stérilité de la femme ou d'un renversement d'alliances, sont condamnées. Hincmar de Reims présente l'anneau des conjoints comme le "symbole de la fidélité et de l'amour et le lien de l'unité conjugale, afin que "l'homme ne sépare pas ce que Dieu a uni" (Mt, 19,6)". La détermination du clergé sur l'indissolubilité transparaît dans l'histoire de Pierre $(† 1115)$, évêque de Poitiers, refusant de lever l'excommunication qu'il a portée contre Guillaume IX d'Aquitaine pour son remariage; la pression du duc n'ébranle pas son entêtement, comme il ressort de l'épitaphe de son tombeau de l'église Saint-Cyprien : "Ni la captivité, ni les chaînes, ni la menace, ni la ruine de son église ne le firent fléchir. (...) Il refusa de défaire les liens qu'il avait formés ${ }^{101}$. " La prohibition de la polygynie est souvent une pierre d'achoppement dans les relations entre les nobles et les clercs.

Les canonistes s'en prennent, en outre, à l'endogamie ou «inceste», sujet auquel Patrick Corbet vient de consacrer un mémoire d'habilitation ${ }^{102}$. C'est le royaume de Germanie qui est à la pointe de la répression du mariage consanguin. Certes, Raban Maur $(\$ 865)$ adopte encore une attitude relativement souple sur l'étendue du champ de parenté à l'intérieur duquel il est interdit de se marier. Mais, dès la fin du $\mathrm{IX}^{\mathrm{e}} \mathrm{s}$., la position des Fausses décrétales, prohibant toutes noces en deçà du septième degré de la computation germanique, l'emporte. La collection canonique de Burchard (1000-1025), évêque de Worms, confirme cet interdit, des plus restrictifs, qui empêche toute alliance entre des consanguins et affins qui auraient un ancêtre commun parmi les ascendants des sept générations antérieures. Par la suite, les grégoriens, souvent issus du monachisme germanique, font de ce principe l'un de leurs chevaux de bataille. Les tribunaux ecclésiastiques combattent désormais avec intensité l'endogamie : en Allemagne, les sources mentionnent seize

95. P. CoRBl:T, "Le mariage en Germanic ottonienne d’après Thietmar de Mersebourg", dans La femme au Moyen Âge. éd. M. Rouchi: et J. Heccils. Maubeuge, 1990. p. 187-215.

96. S. Farmi:k. "Persuasive Wives : Clerical Images of Medieval Wives ». Speculum. 61. 1986. p. 517-543.

97. H. Pl.Atri..... "L Lépouse "gardienne aimante de la vie et de laame de son mari". Quelques exemples du Haut Moven Âge ». dans La femme (voir n. 95). p. 171-185.

98. Aurtil.. Les noces (voir n. 32). p. 310-314.

99. J.-H. Fovion, "L Lecclésiologie du concile de Clermont : Ecclesia sit catholica, casta et libera". dans le concile de Clermomt de 1095 et lappel à la croisade. Rome. 1997. p. 85-125.

100. B. Bastevant-Gatdemet, "I.e principe de lindissolubilité du mariage el les difficultés de son application pratique ", dans La femme au moven âge, Paris. 1992 (Collection des journées de la Faculté de Droit Jean-Monnet). p. 35-46.

101. F. VII.lari), "Guillaume IX d'Aquitaine et le concile de Reims de 1119 ". Cahiers de civilisation médiévale, 15. 1973. p. 169: - G. BEECH. "The Biography and the Study of 1lth Century Society: Bishop Peter II of Poitiers (1087-1115) ». Francia. 7. 1977. p. 101-121.

102. Autour de Burchard de Worms : IÉglise allemande et les interdits de parenté (ax-xir siécles), Université de Nancy II. 1998 [sous presse]. 
mariages mis en cause pour inceste entre 1000 et 1085 . L'idée d'Augustin, d'après laquelle le mariage avec une étrangère diffuse la charité (dilatatio caritatis) bien au-delà du cercle étroit de la famille. est mise en avant pour justifier l'empêchement de parenté, qui heurte de front les intérêts patrimoniaux de l'aristocratie et la paysannerie aisée. On utilise même l'argument cugénique et tératologique, que Grégoire le Grand $(\doteqdot 604)$ ou Gratien formulent de façon explicite. A partir des années 1050, cependant. les princes méridionaux commencent à se servir de l'interdit de l'inceste pour constater la nullité de leur mariage devant les tribunaux ecclésiastiques, ce qui leur permet de répudier à bon compte leur épouse 103 . En attendant ces manœuvres, la mise en avant de l'interdit de parenté n'en atténue pas moins les solidarités lignagères et la cohésion patrimoniale des familles.

C'est dans le rituel nuptial que ce conflit entre les pouvoirs spirituel et temporel se manifeste le plus clairement. Traditionnellement, le père de la mariée était le personnage principal de la cérémonie : il cédait la tutelle de sa fille au futur mari en échange des arrhes que celui-ci lui versait, faisait dresser une charte établissant le douaire, transférait solennellement sa fille de sa demeure à celle du mari, procédait à la jonction des mains droites des mariés et présidait aux festivités. Dans la maison de Guines, il allait jusqu'à prononcer une bénédiction dans la chambre du nouveau couple qui se tenait au lit. Or, au fur et à mesure que le modèle ecclésiastique triomphe, la place du chef du lignage dans la cérémonie rétrécit. Tout au plus intervient-il directement dans les fiançailles, où les engagements, contractés pour une date prochaine (verba de futuro), peuvent faire l'objet de rupture. Il est, en revanche, exclu des noces, où les mariés prononcent les mots du consentement indissoluble au présent (verba de presente).

Le prêtre devient, à sa place, le véritable maître de cérémonies du mariage. Il bénit la chambre nuptiale, aspergeant le lit d'eau bénite et procédant à des exorcismes. Les noces sont, de plus en plus, célébrées à l'ćglise, où il est le seul officiant. Un synode tenu à Rouen en 1012 prescrit : "Que les épousailles ne s'accomplissent pas en secret, ni après le repas, mais que l'époux et l'épouse soient bénis dans l'église par un prêtre à jeun. " Dans la péninsule Ibérique, la richesse des rites wisigothiques privilégic, de même, la fonction sacerdotale. Après que le fiancé a passé l'anneau au quatrième doigt de la jeune fille, d'où l'on croit qu'une veine part vers le cœur, un cortège mène les mariés de la maison vers l'église. À la fin de la messe, le prêtre présente la jeune fille à son époux; il voile, d'abord, le couple de deux draps, l'un rouge et l'autre blanc : les deux couleurs de la vélation symbolisent, respectivement. la fécondité et la chasteté. Il bénit, ensuite, la mariée seule, priant que Dieu lui accorde une abondante progéniture, puis le couple ensemble. Il remet, enfin, la femme au mari, donne encore une bénédiction à la porte de l'église et exhorte les époux à "la nuit de Tobie ", c'est-à-dire à rester chastes jusqu'au lendemain. Dans le domaine des gestes, essenticls aux relations sociales, la victoire éclatante du clergé sur le chef du lignage témoigne de la christianisation des pratiques matrimoniales de l'aristocratic ${ }^{104}$.

L'enjeu de l'appropriation de cette cérémonic est grand. Il est au cœur d'un conflit autour de l'institution matrimoniale. Il reflète les tensions provoquées par l'attachement de certains chefs de lignage à des pratiques ancestrales et par la volonté des clercs de les faire obéir aux commandements évangéliques. Cette éthique, dont les piliers sont la monogamie, l'indissolubilité, le consensualisme et l'exogamie, s'impose progressivement. Quoique opératoire, cette dialectique qui oppose prêtres et guerriers autour du mariage ne saurait cependant être soutenue sous un jour trop tranché : les plus zélés des clercs transmettent par le truchement des épouses une morale conjugale aux laïcs, tandis que les plus indulgents mettent leurs tribunaux au service de la politique matrimoniale de leurs parents. Ces accommodements font souvent l'économic du conflit ouvert. Ils n'existent pas seulement dans l'alliance. mais aussi dans la filiation. Songeons ainsi au parrainage baptismal

103. ("est de la sorte que Pierre le ('hantre (1120/30-1197) stigmatise ce détournement de linstitution : "Flle me plaît. car la dot est grosse. Sans doute mest-elle liée par une affinité au troisième degré. qui neest pourtant pas asse\%. proche pour que je men sépare. mais si je veux. et si elle ne me plaît plus. en raison de cette affinité. je pourrai obtenir le divorce", cité par (3. Di.BY. Le chevalier (voir n. 88). p. 221.

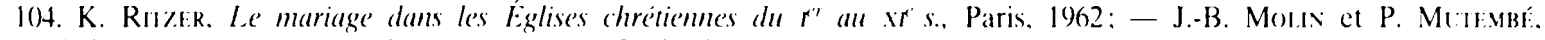
le ritucl du mariage en France du xur aut xir s., Paris. 1974. 
qui influence si profondément la conception que les hommes du moyen âge se font de la famille, et qui subordonne la parenté réelle à la parenté spirituelle ${ }^{105}$. Le modèle laïc et le modèle ecclésiastique connaissent échanges et hybridations.

En l'occurrence, dans toute sa complexité, le problème des liens entre le christianisme et le mariage montre combien il est difficile d'obtenir des certitudes sur l'histoire de la parenté. Marc Bloch l'avait bien compris, qui reprenait l'expression médiévale de "communauté taisible " pour désigner la famille, ses silences et ses secrets, rarement percés. Il n'en demeure pas moins qu'un certain consensus semble se dégager chez les médiévistes autour de la place du cousinage, de son cognatisme et de sa dimension horizontale, pour l'aristocratie des $1 \mathrm{x}^{\mathrm{e}}$ et $\mathrm{x}^{\mathrm{e}} \mathrm{s}$. Le lignage agnatique et sédentaire lui succède aux alentours de l'an mil, d'après des chronologies et des modalités qui varient considérablement selon les régions, mais surtout - pourquoi le cacher ? - selon les grilles d'analyse des historiens actuels et des sources dont ils disposent. Dégager des lignes force pour les stratégies matrimoniales semble une affaire encore plus malaisée. Ne faudrait-il pas, toutefois, associer étroitement l'hypergamie au lignage en raison de l'ascension sociale des chevaliers? Quant à l'action de l'Église, elle entrave assurément la répudiation arbitraire, la polygynie institutionnalisée et l'endogamie entre de très proches parents. Elle est cependant trop en avance pour son temps en matière de consensualisme, alors que l'individu ne compte pas en dehors du groupe et que le mariage est surtout alliance entre deux maisons. Au demeurant, les questions soulevées de nos jours sur la parenté médiévale sont plus nombreuses que les évidences. Pour obtenir des réponses sûres, la recherche doit parvenir à une masse critique de monographies familiales, enracinées sur les régions les plus diverses, construites sur les sources les plus disparates et fondées sur la plus solide méthode prosopographique. L'enjeu est important. En effet, cerner en profondeur la parenté par les formes qu'adoptent la filiation et l'alliance est indispensable pour expliquer les structures mêmes de la société globale. En l'an mil, la famille reste bel et bien la cellule élémentaire de l'organisation sociale.

\author{
Martin Aurell \\ Centre d'Études Supérieures de Civilisation Médiévale \\ 24, rue de la Chaîne \\ F-86022 POITIERS Cedex
}

105. A. Guerreau-Jalabert, «El sistema de parentesco medieval : sus formas (real/espiritual) y su dependencia con respecto a la organización del espacio ». dans Relaciones de poder, de producción y parentesco en la edad média y moderna, éd. R. PASTOR, Madrid, 1990. p. 85-105. Sur cette dissociation entre le discours sur la parenté et les pratiques sociales, cf. également J. MORSE:L. "Geschlecht und Repräsentation: Beobachtungen zur Verwandtschaftskonstruktion im fränkischen Adel des späten Mittelalters ", dans Die Repräsentation der Gruppen. éd. O. G. Orxı.: et A. von Hïısfin-Fscil. Göttingen. 1998. p. 259-325. 